\title{
Expanding Deliberation in Critical-Care Policy Design
}

\section{Govind C. Persad}

To cite this article: Govind C. Persad (2016) Expanding Deliberation in Critical-Care Policy Design, The American Journal of Bioethics, 16:1, 60-63, DOI: 10.1080/15265161.2015.1115566

To link to this article: http://dx.doi.org/10.1080/15265161.2015.1115566

曲 Published online: 06 Jan 2016.

Submit your article to this journal $\widetilde{ }$

Q View related articles $\asymp$

View Crossmark data ¿`

Citing articles: 1 View citing articles ๘ 
scoring in critical illness. Without deliberation about these substantive issues, it is difficult to envisage a successful realization of Kirby's aim to determine a defensible critical care obligation threshold.

\section{SUMMARY AND CONCLUSIONS}

The official policy statement from the ATS ad hoc Committee on Futile and Potentially Inappropriate Treatment aligns as a whole with Kirby's three principles that inform his aim of establishing defensible critical-care limits to lifesustaining treatments. The ATS Policy Statement's emphasis on shared decision making and establishing a process for fair dispute resolution to address differences in value judgments demonstrates a high degree of concordance with Kirby's ethical considerations. However, in order to achieve Kirby's goal of a mutually agreed-upon criticalcare obligation threshold, clinicians will need to not only implement procedural recommendations for dispute resolution, but also meaningfully consider, deliberate, and act on substantive issues such as resource allocation and stewardship concerns.

\section{ACKNOWLEDGMENTS}

The author thanks Maxwell Smith, Michael Szego and Chryssa McAlister for reviewing and editing the commentary.

\section{REFERENCES}

Biddison, L. D., K. A. Berkowitz, B. Courtney, et al., Task Force for Mass Critical Care. 2014. Ethical considerations: Care of the critically ill and injured during pandemics and disasters: CHEST consensus statement. Chest 146(4 suppl.): e145S-55S. http://dx. doi.org/10.1378/chest.14-0742.

Bosslet, G. T., T. M. Pope, G. D. Rubenfeld, et al. 2015. An official ATS/AACN/ACCP/ESICM/SCCM policy statement: Responding to requests for potentially inappropriate treatments in intensive care units. American Journal of Respiratory and Critical Care Medicine 191(11): 1318-30.

Christian, M. D., C. L. Sprung, M. A. King, et al. Task force for mass critical care. 2014. Triage: care of the critically ill and injured during pandemics and disasters: CHEST consensus statement. Chest 146(4 suppl.): 361S-74S. http://dx.doi.org/10.1378/ chest.14-0736.

College of Physicians and Surgeons of Ontario. 2015. Planning for and providing quality end-of-life care. Policy statement 4-15. Available at: http://www.cpso.on.ca/CPSO/media/documents/ Policies/Policy-Items/End-of-Life.pdf?ext=.pdf (accessed October 24, 2015).

Kirby, J. 2016. Balancing legitimate critical-care interests: Setting defensible care limits through policy development. American Journal of Bioethics 16(1): 38-47.

Luce, J. M., and G. D. Rubenfeld. 2002. Can health care costs be reduced by limiting intensive care at the end of life? American Journal of Respiratory Critical Care Medicine 165:750-54.

Luce, J. M., and D. B. White. 2007. The pressure to withhold or withdraw life-sustaining therapy from critically ill patients in the United States. American Journal of Respiratory Critical Care Medicine 175:1104-8.

Wilcox, M. E., and G. D. Rubenfeld. 2015. Is critical care ready for an economic surrogate endpoint? Critical Care 19(1): 248.

\section{Expanding Deliberation in Critical-Care Policy Design}

\section{Govind C. Persad, Georgetown University}

Jeffrey Kirby's (2016) insightful contribution suggests that critical-care decisions should be responsive to the interests of multiple stakeholders, and that deliberative engagement can help achieve this goal. I agree. In this commentary, I suggest expanding on Kirby's account of critical care policy development in two ways. Critical-care policy development should expand the scope of deliberation by leaving fewer issues up to expertise or private choice, and it should broaden both the set of costs considered and the set of stakeholders represented in the deliberative process.

\section{EXPANDING THE SCOPE OF DELIBERATION}

Kirby's article suggests that decisions in some scenarios can be made without engaging in a deliberative process. Discussed scenarios include "futility-type scenarios that are strictly physiological in nature, where the relevant scientific expertise of critical-care clinicians supports their role as determinative decision makers" (40), and the informed refusal of medical interventions. The article also suggests that various factors, such as age, social position,

Address correspondence to Govind C. Persad, McDonough School of Business, Georgetown University, 37th and O St. NW, Rafik B. Hariri Bldg., Washington, DC 20057, USA. E-mail: gpersad@stanfordalumni.org 
psychological well-being, and disability, should be excluded from consideration.

These claims are all contestable. Consider physiological futility. To religious believers who endorse the "possibility of miracles being granted by a sovereign and omnipotent deity" (39), futility is not "strictly physiological in nature" (40) and clinicians should not be accepted as ultimate authorities on the basis of their scientific expertise. Although I agree that physiologically futile care should not be provided, I see refusing to provide futile care as motivated by the same principle as refusing to provide high-cost, low-benefit interventions. The religious believer should not receive futile critical care interventions because she cannot justify her claim to others who need those interventions and could receive them instead. But the same is true for the nonreligious patient seeking an intervention with high costs and low benefits. Neither refusal is justified purely by scientific expertise. Rather, as a recent report of a futility scenario observes, refusing to provide futile care rests on the ethical principle that "an acceptable way to distribute scarce resources would be to distribute them only to people who can benefit from them" (Danis et al. 2012, 174).

Similarly, though it is certainly "important to reduce the risk of discriminatory or arbitrary treatment of patients at the clinical bedside" (41), which factors are discriminatory or arbitrary cannot be predetermined, but will ultimately need to be settled through deliberation. There are compelling arguments for considering age in medical resource allocation (Daniels 2007, 17781). Some guidelines for the provision of major surgical procedures consider psychosocial factors, such as family support, psychological health, and social role (Giacomini et al. 2001, 636-37). Lastly, the observation that "neither people with nor those without disabilities have epistemic access to the 'true' enjoyment of life with a disability" (Bagenstos and Schlanger 2007, 776) complicates any assertion that the public categorically "underestimate[s]" the quality of life of chronically ill patients (61). Instead, members of the non-disabled public disagree with chronically ill patients regarding how quality of life should be assessed; deliberation might help resolve that disagreement.

An informed refusal of medical interventions may seem like the paradigm case of a medical choice in which solely the patient, and no other deliberator, has a morally legitimate interest. However, such refusals can also affect the interest of third parties, such as dependent children whose parents refuse blood transfusions and members of the general public who will ultimately pay to treat Medicaid recipients who refuse amputations; Robert Veatch hypothesizes that some such "third-party interests will eventually be seen as legitimate, while others will not" (Veatch 1993, 8). Deliberation represents a promising way of determining which third-party interests we should regard as legitimate.

\section{EXPANDING THE COSTS DELIBERATED ABOUT}

Relying on a 2002 article by Luce and Rubenfeld (2002), the article concludes that "there is little evidence that health care costs can be reduced appreciably by limiting health care at the end of life" due to the "fixed nature of staffing and infrastructure costs" (41), and that there is a "lack of evidence to indicate that placing limits on the provision of critical care has significant impacts on organizational or overall health care system costs" (43). To some, this would be a happy outcome: We can provide as much end-of-life health care as we like without setting back other social objectives. In contrast, I find it deeply disappointing: In searching for resources to improve access to important goods that help individuals develop their capabilities, including not only health care but education, housing, and infrastructure, we cannot look to end-of-life care reforms as a potential source of money.

Whether fortunately or unfortunately, the conclusion that there is no trade-off between critical care spending and other spending warrants skepticism. First, there are no fixed costs in the long run (Curtis et al. 2012, 588). Luce and Rubenfeld (2002) concede that "ICU costs can be saved by closing beds or not opening them in the first place, as is the approach taken in countries with limited health care resources" (753). No country has unlimited health care resources. And, especially in a global health context, preventing the diversion of resources from the public health sector rather than allowing their diversion to pay for highcost critical care interventions could substantially increase the quantity of benefit a health system can provide for a given cost (Schmidt, Gostin, and Emanuel 2015, 928).

Additionally, even in the short run, critical care involves many large costs that have variable components. For instance, the cost of treating sepsis using activated protein $C$ is nearly a million dollars per quality-adjusted life year (QALY) for some patient groups (Talmor 2006, 2740). Further, advance care planning regarding end-of-life care may be able to realize appreciable savings (Klingler, in der Schmitten, and Marckmann 2015, 9). A recent reply to Luce and Rubenfeld (2002) contends that a reexamination of their conclusions is warranted (Curtis et al. 2012, 587). These dissenting views render the sweeping claim that placing limits on critical care will not save money sufficiently debatable to make it a shaky foundation for policy development.

\section{EXPANDING THE SET OF DELIBERATORS}

Ensuring the "engagement of affected individuals" (38) in critical-care decision-making processes and ensuring that critical-care decision making not "reflect the entrenched biases and ideologies of those who are situated at the top of health care delivery hierarchies" (44) are both desirable goals. However, the deliberative process also must represent individuals entirely unaffiliated with the provision of critical care. I would have liked to see more of this in 
Kirby's proposal, in which the only individuals included in the deliberative process but not explicitly affiliated with the health care system are unspecified "public members." In contrast, numerous stakeholders who directly participate in and benefit from the delivery of critical careincluding former patients, family members of deceased patients, and critical-care providers-are explicitly included. The experts included, meanwhile, are health care administrators, health lawyers, and health care ethicists, rather than similar professionals outside the health sector.

A deliberative working group comprised primarily of critical-care providers and patients, and of health care professionals more generally, will face serious challenges when it comes to responsibly setting limits on the provision of critical care. First, providers and patients may see limits as contrary to their own interests (Persad 2015, 124-25). Even if money spent on family medicine consultations or healthier school lunches does more to promote health or other important societal aims than the same amount spent in the ICU, those other interventions do little for the person in the ICU bed right now, nor do they require the skills of ICU physicians. Second, critical-care providers have no special expertise in evaluating the benefits of their own interventions compared to others, and indeed specialists have in general proven likely to rate the value of their own specialty higher than others do (Morden et al. 2014, 590). Third, without a concerted effort to recruit members of the public who are unaffiliated with the health care system, the public members who ultimately end up participating in the deliberative process are likely to be those with preexisting relationships with, and stakes in, particular interests within the health care system. These problems are not unique to critical care policy development, and are widely recognized as challenges for public engagement in health care (Charles and DeMaio 1993, 891-93).

As an alternative, I would suggest the development of critical-care decision-making policies by a deliberative body that more fully represents the interests of the broader polity who are affected by, and have a stake in, choices about critical-care provision. In doing so, we might look to the work of researchers who, using a deliberative democracy methodology, interviewed members of the public regarding how critical care and other resources should be allocated in an influenza pandemic; interestingly, these researchers excluded "healthcare workers ... because of concerns that they might dominate or bias the dialogue" (Daugherty Biddison et al. 2014, 778). Another recent proposal suggests having policies be developed by "single-issue legislatures" selected randomly from the population; such bodies would hear from individuals with relevant expertise, such as doctors and former patients, but ultimately reach the decision based on their own values (Guerrero 2014, 154-63). Both these strategies require soliciting the informed opinions of members of the general public rather than giving primacy to those within the health care system. Such strategies could realize the benefits of deliberation without having critical-care decision-making policies made primarily by participants in, or beneficiaries of, critical-care provision.

\section{ACKNOWLEDGMENTS}

I am grateful to Amy Saltzman and to Wendy Salkin for their suggestions on an earlier draft.

\section{REFERENCES}

Bagenstos, S. R., and M. Schlanger. 2007. Hedonic damages, hedonic adaptation, and disability. Vanderbilt Law Review 60(3): 745-97.

Charles, C., and S. DeMaio. 1993. Lay participation in health care decision making: A conceptual framework. Journal of Health Politics, Policy and Law 18(4): 881-904.

Curtis, J. R., R. A. Engelberg, M. E. Bensink, et al. 2012. End-of-life care in the intensive care unit: Can we simultaneously increase quality and reduce costs? American Journal of Respiratory and Critical Care Medicine 186(7): 587-92.

Daniels, N. 2007. Just health: Meeting health needs fairly. Cambridge, UK: Cambridge University Press.

Danis, M., E. Largent, C. Grady, et al. 2012. Research ethics consultation: A casebook. New York, NY: Oxford University Press.

Daugherty Biddison, E. L., H. Gwon, M. Schoch-Spana, et al. 2014. The community speaks: Understanding ethical values in allocation of scarce lifesaving resources during disasters. Annals of the American Thoracic Society 11(5): 777-83.

Giacomini, M. K., D. J. Cook, D. L. Steiner, et al. 2001. Guidelines as rationing tools: a qualitative analysis of psychosocial patient selection criteria for cardiac procedures. Canadian Medical Association Journal 164(5): 634-40.

Guerrero, A. A. 2014. Against elections: The lottocratic alternative. Philosophy \& Public Affairs 42(2): 135-78.

Kirby, J. 2016. Balancing legitimate critical-care interests: Setting defensible care limits through policy development. American Journal of Bioethics 16(1): 38-47.

Klingler, C., in der Schmitten, J., and Marckmann, G. 2015. Does facilitated advance care planning reduce the costs of care near the end of life? Systematic review and ethical considerations. Palliative Medicine. Available at: http://pmj.sagepub.com/ content/early/2015/08/20/0269216315601346.abstract. doi: $10.1177 / 0269216315601346$

Luce, J. M., and G. D. Rubenfeld. 2002. Can health care costs be reduced by limiting intensive care at the end of life? American Journal of Respiratory and Critical Care Medicine 165(6): 750-54.

Morden, N. E., C. H. Colla, T. D. Sequist, et al. 2014. Choosing wisely-The politics and economics of labeling low-value services. New England Journal of Medicine 370(7): 589-92. 
Persad, G. 2015. Priority setting, cost-effectiveness, and the affordable care act. American Journal of Law \& Medicine 41(1): 119-66.

Schmidt, H., L. O. Gostin, and E. J. Emanuel. 2015. Public health, universal health coverage, and sustainable development goals: Can they coexist? Lancet 386(9996): 928-30.
Talmor, D., N. Shapiro, D. Greenberg, et al. 2006. When is critical care medicine cost-effective? A systematic review of the cost-effectiveness literature. Critical Care Medicine 34(11): 2738-47.

Veatch, R. M. 1993. Forgoing life-sustaining treatment: Limits to the consensus. Kennedy Institute of Ethics Journal 3(1): 1-19. 